\title{
Psychedelics and potential benefits in "healthy normals": A review of the literature
}

\author{
SAM GANDY* \\ Independent Researcher, Leicestershire, UK
}

(Received: April 30, 2019; accepted: October 24, 2019)

\begin{abstract}
We are in the midst of a psychedelic research renaissance. With research examining the efficacy of psychedelics as a treatment for a range of mental health indications still in its early stages, there is an increasing body of research to show that careful use of psychedelics can yield a variety of benefits in "healthy normals" and so lead to "the betterment of well people." Psychedelics have been found to modulate neuroplasticity, and usage in a supportive setting can result in enduring increases in traits such as well-being, life satisfaction, life meaning, mindfulness, and a variety of measures associated with prosocial behaviors and healthy psychological functioning. The effect of psychedelic experience on measures of personality trait openness and is potential implications is examined, and the potential role of awe as a mediator of the benefits of the psychedelic experience is discussed. Special attention is given to the capacity of psychedelics to increase measures of nature relatedness in an enduring sense, which is being correlated with a broad range of measures of psychological well-being as well as a key predictor of pro-environmental awareness and behavior. The effects of particular classical psychedelic compounds on healthy people are discussed, with special attention given to the mystical-type experiences occasioned by high doses of psychedelics, which appear to be an important mediator of long-term benefits and psychotherapeutic gains. Research looking at the potential benefits of psychedelic microdosing is discussed. Potential future research avenues are explored, focusing on the potential development of psychedelics as agents of ecotherapy.
\end{abstract}

Keywords: psychedelics, benefits, nature, psilocybin, LSD, ayahuasca

\section{INTRODUCTION}

Classical or serotonergic psychedelic compounds are a subclass of psychedelic compounds whose method of action is strongly tied to the neurotransmitter serotonin, with the compounds acting as partial agonists at the serotonin $5-\mathrm{HT}_{2 \mathrm{~A}}$ receptor, which is widely distributed across numerous cortical areas of the brain (Carhart-Harris et al., 2014; Glennon, Titeler, \& McKenney, 1984). They are known for their very low physiological toxicity, being non-addictive, and exerting profound effects on human consciousness. Examples of classical psychedelics include DMT, LSD, psilocybin, mescaline, and compounds of the $2 \mathrm{C}$ family. The tryptamine psychedelics such as DMT and psilocybin structurally resemble serotonin itself, whereas mescaline and compounds of the $2 \mathrm{C}$ family resemble the neurotransmitter dopamine in structure. Psychedelics, such as psilocybin, mescaline, DMT, and lysergic acid compounds, have been employed for purposes of healing and divination by some cultures for centuries if not millennia (Nichols, 2016). We are in the midst of a psychedelic renaissance, with scientific research into the properties of these compounds expanding rapidly (Sessa, 2018). Although much of this current research has been focused on their medical potential, there is an increasing body of evidence on the effect of psychedelics on "healthy normal" people without a specific mental health diagnosis (a good proportion of which may be psychedelic naive), and this research suggests a number of potential benefits of controlled psychedelic use among this population on cognition, awareness, and well-being. A large-scale survey study found that there were no significant associations between lifetime use of classical psychedelics and rate of poor mental health outcomes, and psychedelic usage may in fact confer mental health benefits (Krebs \& Johansen, 2013). A further population study of 130,000 adults in the US failed to find any evidence for a link between usage of classical psychedelics and mental health problems (Johansen \& Krebs, 2015). Lifetime use of classical psychedelics has been associated with significantly reduced odds of past-month psychological distress, past-year suicidal planning, and past-year suicide attempt likelihood, unlike lifetime illicit use of other drugs, which was largely associated with increased likelihood of these outcomes, suggesting psychedelics may hold promise in the prevention of suicide (Hendricks, Thorne, \& Clark, 2015). Lifetime use of classical psychedelics has also been associated with reduced odds of antisocial criminal behavior (Hendricks et al., 2018). Long-term regular ritualistic use of peyote among Native Americans has not been associated with any psychological or cognitive deficits (Halpern, Sherwood, Hudson, Yurgelun-Todd, \& Pope, 2005).

\footnotetext{
* Corresponding address: Dr. Sam Gandy; Independent Researcher, Farndon Grange, Marston Lane, Market Harborough, Leicestershire LE16 9SL, UK; Phone: +44 7971894 662; E-mail: greensam2512@ hotmail.com
}

This is an open-access article distributed under the terms of the Creative Commons Attribution-NonCommercial 4.0 International License, which permits unrestricted use, distribution, and reproduction in any medium for non-commercial purposes, provided the original author and source are credited, a link to the CC License is provided, and changes - if any - are indicated. 
Psychedelics have been implicated in promoting structural neural plasticity, by robustly increasing the formation of new synapses and dendrites between neurons, facilitating the formation of new synapses and dendrites between neurons. These neuroplastic properties could at least partly explain their long-term therapeutic potency, with the label "psychoplastogen" being applied to them (Ly et al., 2018), with neuroplasticity believed to be a key mechanism in learning and adaptation, and the brain's ability to modify and change both structure and function throughout life in response to experience (Voss, Thomas, Cisneros-Franco, \& de Villers-Sidani, 2017).

A correlative study assessing the values, beliefs, and emotional empathy of psychedelic users found increased values of spirituality and concern for others and lower appreciation of financial prosperity, although it is hard to say whether these values preceded psychedelic usage or resulted from it (Lerner \& Lyvers, 2006). Other studies have found psychedelic users to show greater creativity than non-users (Sweat, Bates, \& Hendricks, 2016), and lifetime use of psychedelics to positively predicts liberal political views, openness, and nature relatedness, while negatively predicting authoritarian political views (Nour, Evans, \& Carhart-Harris, 2017).

Psychedelic usage may help facilitate creative pursuits (Sessa, 2008) and both artists and scientists have reported valuable insights as a result of psychedelic experiences (Narby, 2002; Sessa, 2008). One study using mescaline with scientists and engineers working on creative problems found that the engineers reported an enduring positive impact on their creative process (Harman, McKim, \& Mogar, 1966). One study reported that lifetime use of classical psychedelics (but not that of other substances examined) was found to predict pro-environmental behavior through an increase in nature relatedness, or connectedness, which can be viewed as one's self identification with nature (Forstmann \& Sagioglou, 2017).

There is a substantial body of literature reporting a positive correlation between nature relatedness and a broad range of measures of psychological well-being. Nature relatedness has been found to correlate with lower levels of anxiety (Capaldi, Dopko, \& Zelenksi, 2014; Martyn \& Brymer, 2016); greater happiness and positive affect (Capaldi et al., 2014; Nisbet, Zelenksi, \& Murphy, 2011; Pritchard, Richardson, Sheffield, \& McEwan 2019; Zelenski \& Nisbet, 2014); life meaning and vitality (Cervinka, Röderer, \& Hefler, 2012), and improved psychological well-being at the state and trait level (Capaldi et al., 2014; Capaldi, Passmore, Nisbet, Zelenksi, \& Dopko, 2015; Cervinka et al., 2012; Dean et al., 2018; Howell, Dopko, Passmore, \& Buro, 2011; Kamitsis \& Francis, 2013; Mayer \& Frantz, 2004; Mayer, Frantz, Bruehlman-Senecal, \& Dolliver 2008; Nisbet \& Zelenski, 2014; Van Gordon, Shonin, \& Richardson, 2018; Zelenski \& Nisbet, 2014). Nature relatedness has also been found to mediate the effect of nature exposure or immersion on affect, with more positive outcomes of nature exposure observed in those who rate high in nature relatedness (McMahan, Estes, Murfin, \& Bryan, 2018) while also acting as a mediator of the perceived restorativeness of natural settings (Berto, Barbiero, Barbiero, \& Senes, 2018). Measures of well-being were also found to be partially mediated by degree of nature relatedness in response to perceiving natural beauty (Zhang, Howell, \& Iyer, 2014), and nature relatedness may also elicit higher valuating of intrinsic aspirations following exposure to nature (Weinstein, Przybylski, \& Ryan, 2009).

Nature relatedness has also been found to strongly predict pro-environmental awareness (Dutcher, Finley, Lulogg, \& Johnson, 2007; Mackay \& Schmitt, 2019; Mayer \& Frantz, 2004; Restall \& Conrad, 2015; Whitburn, Linklater, \& Abrahamse, 2019) being perhaps the single strongest psychological predictor of pro-environmental behavior (Otto \& Pensini, 2017). This is an important finding given that it is widely considered we are experiencing the sixth mass extinction of life on this planet due to human actions on the biosphere (Barnosky et al., 2011; Ceballos, Ehrlich, \& Dirzo 2017; Dirzo et al., 2014; McCallum, 2015). Pro-environmental behavior appears strongly linked to prosocial behavior, sharing a mutually enhancing relationship, with an increase in one fostering an increase in the other (Neaman, Otto, \& Vinokur, 2018).

Psilocybin has been found to result in increases in nature relatedness in patients with treatment-resistant depression up to 7-12 months post-experience (Lyons \& CarhartHarris, 2018). A study pooling data from eight different trials administering psilocybin to healthy volunteers found that $38 \%$ of people reported enduring positive changes in their relations to nature and the environment (Studerus, Kometer, Hasler, \& Vollenweider, 2011) 8-16 months post-experience. This occurred in spite of the clinical, nature-deprived settings the trials were conducted in, which included a PET scanner, suggesting that such enduring changes to one's relationship with nature are not entirely dependent on the setting in which the experience occurs. In a classic study known as "The Good Friday Experiment," high-dose psilocybin was administered to divinity students, with the majority reporting a complete mystical experience (Pahnke, 1963). A follow-up interview survey conducted between 24 and 27 years after the original study revealed that study participants felt strongly that they had continued to benefit from their experience, reporting a deepened appreciation of life and nature, as well as enhanced joy, a deepened sense of spirituality, and appreciation for unusual experiences and emotions (Doblin, 1991). Numerous modern research studies in both healthy (Griffiths et al., 2011; Griffiths, Richards, McCann, \& Jesse, 2006; MacLean, Johnson, \& Griffiths, 2011) and patient (Carhart-Harris et al., 2018; Garcia-Romeu, Griffiths, \& Johnson, 2016; Griffiths et al., 2016; Ross et al., 2016) populations have found that the occurrence of a mystical-type experience during a psychedelic session is a key mediator of long-term therapeutic gains and benefits post-session. Psychedelic usage has been implicated to evoke experiences of "God" or "Ultimate Reality," with a study on psychedelic users and people who have had such experiences while sober reporting that two thirds of both groups stated they no longer identified as atheists following their experience. Such experiences were associated with long-term increases in life satisfaction, purpose and meaning, and a decreased fear of death (Griffiths, Hurwitz, Davis, Johnson, \& Jesse, 2019).

The experience of ego dissolution, which can occur to people under high dosages of psychedelics, appears to be 
tied to the experience of awe, which may be a mediator of their beneficial effect (Hendricks, 2018), with the experience of awe being linked to both enhanced well-being (Rudd, Vohs, \& Aaker, 2012) and prosociality (Piff, Dietze, Feinberg, Stancato, \& Keltner, 2015), two aftereffects commonly noted following psychedelic experiences, and particularly the mystical-type experiences they can occasion (Griffiths et al., 2006, 2011, 2018; Hendricks, 2018).

\section{PSILOCYBIN}

The psychedelic research renaissance was largely reignited by the publication of Roland Griffiths and the Johns Hopkins team's seminal paper on psilocybin and mystical experiences in 2006. The study participants were welleducated, healthy people with an interest in spiritual or religious practices. The study used a rigorous double-blind design and used community observer ratings to gain a more objective measure of post-psilocybin changes. At 2 months after the session, $67 \%$ of study participants rated the highdose psilocybin experience to be either the single most meaningful experience of their lives, or among the top five most meaningful experiences, with $33 \%$ of people rating it as the single most spiritually significant event of their lives (Griffiths et al., 2006). In another study conducted on healthy, psychedelic-naive subjects by the Johns Hopkins team, high-dose psilocybin sessions evoked mystical-type experiences in $72 \%$ of volunteers and resulted in sustained positive changes in attitudes, mood, and behavior, with ascending dosage correlated with greater positive effects. At 14 months after dosing, ratings were undiminished and were consistent with changes rated by community observers, with $94 \%$ of study volunteers stating that their wellbeing or life satisfaction had been increased moderately or very much by their psilocybin experiences, with $89 \%$ reporting moderate or higher changes in positive behavior. Persistent positive changes in attitude, mood, and life satisfaction catalyzed by psilocybin-induced mystical experiences appear similar to those following spontaneous mystical experiences (Griffiths et al., 2011).

The mystical-type experiences associated with psilocybin have also been implicated with leading to long-term increases in personality trait openness, and at 14 months following dosing in the aforementioned study participant group, openness remains significantly elevated (MacLean et al., 2011). This is significant, as openness was believed to be fixed by the age of 30 years and to decline with age. Openness is correlated with a number of cognitive abilities, and appreciation for new experiences and aesthetics, creativity, imagination, hunger for knowledge, broadminded tolerance of the viewpoints, and values of others (MacLean et al., 2011) and increased cognitive reserve in the older people (Franchow, Suchy, Thorgusen, \& Williams, 2013). In addition, it correlates with nature connection and pro-environmental behavior (Lee, Ashton, Choi, \& Zachariassen, 2015; Richardson \& Sheffield, 2015; Tam, 2013). A recent double-blind study with healthy participants explored the effect of a number of meditation or spiritual practices in combination with psilocybin sessions (Griffiths et al., 2018). Participants embarked upon a given spiritual practice 1-2 months prior to their psilocybin (or placebo) sessions. High-dose psilocybin was found to produce greater persisting effects, and at 6-months follow-up of dosing, high-dose groups showed significant large positive changes in prosocial attitudes and behaviors and healthy psychological functioning, including in measures of interpersonal closeness, gratitude, life meaning/purpose, forgiveness, death transcendence, daily spiritual experiences, and religious faith and coping, with changes validated further by external community observer ratings. Determinants of enduring positive effects were the psilocybin-occasioned mystical-type experience and rates of meditation/spiritual practices. Other research has found a synergy between psilocybin and meditation practice, with psilocybin increasing meditation depth, incidence of positive experienced ego-dissolution and enhancing mindfulness and psychosocial functioning (Smigielski, Kometer, et al., 2019), extent of ego dissolution and brain connectivity predicting positive changes in psycho-social functioning of participants 4 months post-session (Smigielski, Scheiddegger, Kometer, \& Vollenweider, 2019). Previous research suggests that psychedelics can help foster psychological growth when used in the context of an ongoing discipline (Walsh, 1982).

\section{LSD}

A study on healthy people who had complained of a lack of purpose or meaning in their lives found that a supervised LSD session resulted in higher self-reported measures of self-actualization and creativity, with participants reporting a greater sense of meaning and purpose in their lives, oneness with humanity, decreased valuation of superficial pursuits such as material gains and social status, and an increase in confidence and assertiveness, with many of these changes still apparent months later (Savage, Fadiman, \& Mogar, 1966).

Modern research has found that an LSD experience in a controlled setting can result in elevated levels of optimism and trait openness 2 weeks post-experience (Carhart-Harris et al., 2016). The administration of a single large $(200 \mu \mathrm{g})$ dose of LSD in a supportive setting to 16 healthy participants was found to lead to increases in positive attitudes about life and/or self, positive mood changes, altruistic/ positive social effects, positive behavioral changes, and well-being/life satisfaction at 1 and 12 months following dosing, with no negative effects on attitudes or behavior attributed to the LSD experience. After 12 months, 10 of 14 participants rated their LSD experience as among the top 10 most meaningful experiences of their lives, with five rating the experience as among the most meaningful experiences of their lives (Schmid \& Liechti, 2018).

\section{AYAHUASCA}

Ayahuasca use in a ritual setting is considered safe and may confer benefits (Barbosa, Mizumoto, Bogenschutz, \& Strassman 2012), with lower rates of alcoholism and addiction observed among ritualistic users (Fábregas et al., 2010). 
Its use has been associated with long-term beneficial changes such as lower ratings on all psychopathology measures, with higher ratings of life purpose, well-being, and prosocial behavior as compared to non-ayahuascausing controls (Bouso et al., 2012). Additional research has found long-term ayahuasca use to be associated with higher positive perception of health and healthy life style, and reduced intake of prescription drugs (Ona et al., 2019). Ayahuasca usage has also been found to increase measures of "acceptance" (associated with a more detached and less judgmental stance toward potentially distressing thoughts and emotions) as effectively as an 8-week mindfulness course, a more lengthy and costly intervention (Soler et al., 2016). Ayahuasca usage has been linked to reductions in stress and improvements in convergent thinking 4 weeks post experience (Uthuag et al., 2019). Repeated ingestion of ayahuasca in a ritual setting has been found to increase visual creativity (Frecska, Móré, \& Vargha, 2012). Ayahuasca users have been found to rate more highly in self-transcendence (Bouso et al., 2012), which has been found to be a significant positive predictor for nature relatedness and environmental concern (Dornhoff, Sothmann, Fiebelkorn, \& Menzel, 2019).

Anthropologist Jeremy Narby accompanied three molecular biologists to the Amazon rainforest where they partook of an ayahuasca ceremony. While all three found the experience to be personally meaningful, two of the three gained perspectives on their research they considered valuable following the session (Grant, 2006).

\section{5-MEO-DMT}

An online survey study reported that the psychedelic compound 5-MeO-DMT was commonly used infrequently and primarily for spiritual exploration, and was welltolerated with very few problems associated with usage (Davis, Barsuglia, Lancelotta, Grant, \& Renn, 2018). The use of 5-MeO-DMT (in the form of vaped Incilius alvarius toad secretion) in a naturalistic setting has been implicated in unintended but substantial reductions in measures of depression (80\%) and anxiety (79\%). Its usage in naturalistic settings has also been implicated in increasing measures of well-being and mindfulness long term (with the latter measure gaining statistical significance a month after dosing), with long-term benefits correlating with a greater intensity of mystical experiences and higher ratings of spiritual significance and personal meaning (Davis, So, Lancelotta, Barsuglia, \& Griffiths, 2019). A single inhalation of 5-MeO-DMT (again in the form of vaped I. alvarius toad secretion) resulted in a significant increase in ratings of life satisfaction and convergent thinking immediately after intake, and was sustained at follow-up 4 weeks later. Ratings of mindfulness increased over time and attained statistical significance at 4 weeks. Ratings of depression, anxiety, and stress decreased after the sessions and reached significance at 4 weeks. High levels of ego dissolution and oceanic boundlessness during the experience were correlated with higher ratings for life satisfaction and lower ratings of depression and stress (Uthaug et al., 2019). The short lasting effects of 5-MeO-DMT and its consistency in inducing mystical-type experiences, which have been implicated in long-term benefits and therapeutic gains, are notable (Barsuglia et al., 2018).

\section{PSYCHEDELIC MICRODOSING}

Research on psychedelic microdosing is still in its preliminary stages, but studies conducted to date warrant further research. Surveys of psychedelic microdosers have yielded reported benefits of improved mood, cognition, and creativity, which in some cases help counteract symptoms of depression and anxiety, although various challenges were also associated with the practice (Anderson, Petranker, Christopher, et al., 2019; Johnstad, 2018). One observational study found that microdosing was associated with a general increase in reported psychological functioning on dosing days, but little evidence of residual effects on following days. Analyses of pre- and post-study measures showed reduced levels of depression and stress, lower levels of distractibility, increased absorption, and increased neuroticism. Effects that were believed likely to manifest were also unrelated to the observed patterns of reported effects (Polito \& Stevenson, 2019). In an additional observational study, former and current microdosers scored lower on measures of dysfunctional attitudes and negative emotionality and higher on measures of wisdom, open-mindedness, and creativity compared to non-microdosing controls (Anderson, Petranker, Rosenbaum, et al., 2019). Microdosing may lead to improvements in convergent and divergent thinking, although further research is warranted using rigorous placebo-controlled study findings to investigate this further (Prochazkova et al., 2018).

\section{FUTURE RESEARCH AVENUES}

There are a number of interesting studies currently underway exploring the effects of psychedelics (psilocybin especially) in healthy people. At present, there is still a lack of knowledge of the prospective, causative role of psychedelics and their effects on cognition, well-being and personality in healthy psychedelic naive people, particularly their longer-term effects. Longer-term qualitative assessments and MRI brain scans comparing psychedelic naive people pre- and post-psychedelic experiences (both shortterm and long-term assessments) would help elucidate the longer-term effects of psychedelics. At present, despite its vast importance for individual well-being and in facilitating pro-environmental awareness, the capacity of psychedelic to enhance nature relatedness in the long term remains under explored. Although there are a number of correlative studies linking psychedelic use to increased nature relatedness, there is only one small study $(n=7)$ that shows a causative, prospective role of psychedelics in increasing nature relatedness, and further prospective research is warranted to explore this in greater detail. Such data could be obtained via online prospective surveys, or via prospective clinical trials, comparing measures of nature relatedness in psychedelic naive people, pre- and post-psychedelic experiences, including longer-term measures. Due to strict regulations 
governing clinical trials of psychedelics at the present time, psychedelic trials are conducted in clinical nature-deprived environments. In the future, it will be interesting to investigate the influence of nature-based settings, and how these may influence measures of nature relatedness and associated well-being. It would also be interesting to conduct a comparative study to see whether ingestion of organic or synthetic psychedelics influences subsequent measures of nature relatedness. Further research is warranted to explore the potential of psychedelics to act as agents of ecotherapy. Given promising past pioneering research findings on psychedelics and creativity among scientists and engineers in the 1960s, modern rigorous research on the potential effect of psychedelics on creativity and divergent thinking is warranted. Research on psychedelic microdosing is still in its preliminary stages, and it would be useful for future clinical studies to investigate the effects of microdosing on biological and cognitive parameters to better evaluate potential beneficial and negative effects, and assess the potential risks of repeated administrations of psychedelics in low doses, using rigorous placebo-controlled study designs.

Conflict of interest: The author declares no conflict of interest.

Acknowledgements: The author has no financial assistance to acknowledge but would like to thank Dr. Rosalind Watts for the inspiration to write the paper.

\section{REFERENCES}

Anderson, T., Petranker, R., Christopher, A., Rosenbaum, D., Weissman, C., Dinh-Williams, L.-A., Hui, K., \& Hapke, E. (2019). Psychedelic microdosing benefits and challenges: An empirical codebook. Harm Reduction Journal, 16(1), 43. doi:10.1186/s12954-019-0308-4

Anderson, T., Petranker, R., Rosenbaum, D., Weissman, C. R., Dinh-Williams, L.-A., Hui, K., Hapke, E., \& Farb, N. A. S. (2019). Microdosing psychedelics: Personality, mental health, and creativity differences in microdosers. Psychopharmacology, 236(2), 731-740. doi:10.1007/s00213-018-5106-2

Barbosa, P. C., Mizumoto, S., Bogenschutz, M. P., \& Strassman, R. J. (2012). Health status of ayahuasca users. Drug Testing and Analysis, 4(7), 601-609.

Barnosky, A. D., Matzke, N., Tomiya, S., Wogan, G. O., Swartz, B., Quental, T. B., Marshall, C., McGuire, J. L., Lindsey, E. L., Maguire, K. C., Mersey, B., \& Ferrer, E. A. (2011). Has the Earth's sixth mass extinction already arrived? Nature, 471(7336), 51-57. doi:10.1038/nature09678

Barsuglia, J., Davis, A. K., Palmer, R., Lancelotta, R., WindhamHerman, A.-W., Peterson, K., Polanco, M., Grant, R., \& Griffiths, R. R. (2018). Intensity of mystical experiences occasioned by $5-\mathrm{MeO}-\mathrm{DMT}$ and comparison with a prior psilocybin study. Frontiers in Psychology, 9, 2459. doi:10.3389/fpsyg. 2018.02459

Berto, R., Barbiero, G., Barbiero, P., \&Senes, G. (2018). An individual's connection to nature can affect perceived restorativeness of natural environments. Some observations about biophilia. Behavioral Sciences (Basel), 8(3), 34. doi:10.3390/ bs 8030034

Bouso, J. C., González, D., Fondevila, S., Cutchet, M., Fernández, X., Ribeiro Barbosa, P. C., Alcázar-Córcoles, M. A., Araújo, W. S., Barbanoj, M. J., Fábregas, J. P., \& Riba, J. (2012). Personality, psychopathology, life attitudes and neuropsychological performance among ritual users of ayahuasca: A longitudinal study. PLoS One, 7(8), e42421. doi:10.1371/ journal.pone. 0042421

Capaldi, C. A., Dopko, R. L., \& Zelenski, J. M. (2014). The relationship between nature connectedness and happiness: A meta-analysis. Frontiers in Psychology, 5, 976. doi:10.3389/ fpsyg.2014.00976

Capaldi, C. A., Passmore, H.-A., Nisbet, E. K., Zelenski, J. M., \& Dopko, R. L. (2015). Flourishing in nature: A review of the benefits of connecting with nature and its application as a wellbeing intervention. International Journal of Wellbeing, 5(4), 1-16. doi:10.5502/ijw.v5i4.449

Carhart-Harris, R. L., Bolstridge, M., Day, C. M. J., Rucker, J., Watts, R., Erritzoe, D. E., Kaelen, M., Giribaldi, B., Bloomfield, M., Pilling, S., Rickard, J. A., Forbes, B., Feilding, A., Taylor, D., Curran, H. V., \& Nutt, D. J. (2018). Psilocybin with psychological support for treatment-resistant depression: Six month follow-up. Psychopharmacology, 235(2), 399-408. doi:10.1007/s00213-017-4771-x

Carhart-Harris, R. L., Kaelen, M., Bolstridge, M., Williams, T. M., Williams, L. T., Underwood, R., Feilding, A., \& Nutt, D. J. (2016). The paradoxical psychological effects of lysergic acid diethylamide (LSD). Psychological Medicine, 46(7), 1379-1390. doi:10.1017/S0033291715002901

Carhart-Harris, R. L., Leech, R., Hellyer, P. J., Shanahan, M., Feilding, A., Tagliazucchi, E., Chialvo, D. R., \& Nutt, D. (2014). The entropic brain: A theory of conscious states informed by neuroimaging research with psychedelic drugs. Frontiers in Human Neuroscience, 8, 20. doi:10.3389/ fnhum.2014.00020

Ceballos, G., Ehrlich, P. R., \& Dirzo, R. (2017). Biological annihilation via the ongoing sixth mass extinction signaled by vertebrate population losses and declines. Proceedings of the National Academy of Sciences of the United States of America, 114(30), E6089-E6096. doi:10.1073/pnas.1704949114

Cervinka, R., Röderer, K., \& Hefler, E. (2012). Are nature lovers happy? On various indicators of well-being and connectedness with nature. Journal of Health Psychology, 17(3), 379-388. doi:10.1177/1359105311416873

Davis, A. K., Barsuglia, J. P., Lancelotta, R., Grant, R. M., \& Renn, E. (2018). The epidemiology of 5-methoxy- $N, N$-dimethyltryptamine (5-MeO-DMT) use: Benefits, consequences, patterns of use, subjective effects, and reasons for consumption. Journal of Psychopharmacology, 32(7), 779-792. doi:10.1177/0269881 118769063

Davis, A. K., So, S, Lancelotta, R., Barsuglia, J. P., \& Griffiths, R. R. (2019). 5-Methoxy- $N, N$-dimethyltryptamine (5-MeO-DMT) used in a naturalistic setting is associated with unintended improvements in depression and anxiety. The American Journal of Drug and Alcohol Abuse, 45(2), 161-169. doi:10.1080/00952990.2018.1545024

Dean, J. H., Shanahan, D. F., Bush, R., Gaston, K. J., Lin, B. B., Barber, E., Franco, L., \& Fuller, R. A. (2018). Is nature relatedness associated with better mental and physical health? 
International Journal of Environmental Research and Public Health, 15(7), 1371. doi:10.3390/ijerph15071371

Dirzo, R., Young, H. S., Galetti, M., Ceballos, G., Isaac, N. J., \& Collen, B. (2014). Defaunation in the anthropocene. Science, 345(6195), 401-406. doi:10.1126/science. 1251817

Doblin, R. (1991). Pahnke's "Good Friday experiment”: A longterm follow-up and methodological critique. The Journal of Transpersonal Psychology, 23(1), 1-28. Retrieved from http:// www.atpweb.org/jtparchive/trps-23-91-01-001.pdf

Dornhoff, M., Sothmann, J.-N., Fiebelkorn, F., \& Menzel, S. (2019). Nature relatedness and environmental concern of young people in Ecuador and Germany. Frontiers in Psychology, 10, 453. doi:10.3389/fpsyg.2019.00453

Dutcher, D. D., Finley, J. C., Luloff, A., \& Johnson, J. B. (2007). Connectivity with nature as a measure of environmental values. Environment and Behavior, 39(4), 474-493. doi:10.1177/ 0013916506298794

Fábregas, J. M., González, D., Fondevila, S., Cutchet, M., Fernández, X., Barbosa, P. C., Alcázar-Córcoles, M. Á., Barbanoj, M. J., Riba, J., \& Bouso, J. C. (2010). Assessment of addiction severity among ritual users of ayahuasca. Drug and Alcohol Dependence, 111(3), 257-261. doi:10.1016/ j.drugalcdep.2010.03.024

Forstmann, M., \& Sagioglou, C. (2017). Lifetime experience with (classic) psychedelics predicts pro-environmental behavior through an increase in nature relatedness. Journal of Psychopharmacology, 31(8), 975-988. doi:10.1177/02698811 17714049

Franchow, E. I., Suchy, Y., Thorgusen, S. R., \& Williams, P. (2013). More than education: Openness to experience contributes to cognitive reserve in older adulthood. Journal of Aging Science, 1(2). doi:10.4172/2329-8847.1000109

Frecska, E., Móré, C. E., \& Vargha, A. (2012). Enhancement of creative expression and entoptic phenomena as after-effects of repeated ayahuasca ceremonies. Journal of Psychoactive Drugs, 44(3), 191-199. doi:10.1080/02791072.2012.703099

Garcia-Romeu, A., Griffiths, R. R., \& Johnson, M. W. (2016). Psilocybin-occasioned mystical experiences in the treatment of tobacco addiction. Current Drug Abuse Reviews, 7(3), 157-164. doi:10.2174/1874473708666150107121331

Glennon, R. A., Titeler, M., \& McKenney, J. D. (1984). Evidence for 5-HT2 involvement in the mechanism of action of hallucinogenic agents. Life Sciences, 35(25), 2505-2511. doi:10.1016/ 0024-3205(84)90436-3

Grant, J. (2006). Discarded science (pp. 185-186). New York, NY: Sterling Publishing

Griffiths, R. R., Hurwitz, E. S., Davis, A. K., Johnson, M. W., \& Jesse, R. (2019). Survey of subjective "God encounter experiences": Comparisons among naturally occurring experiences and those occasioned by the classic psychedelics psilocybin, LSD, ayahuasca, or DMT. PLoS One, 14(4), e0214377. doi:10.1371/journal.pone.0214377

Griffiths, R. R., Johnson, M. W., Carducci, M. A., Umbricht, A., Richards, W. A., Richards, B. D., Cosimano, M. P., \& Klinedinst, M. A. (2016). Psilocybin produces substantial and sustained decreases in depression and anxiety in patients with life-threatening cancer: A randomized double-blind trial. Journal of Psychopharmacology, 30(12), 1181-1197. doi:10.1177/ 0269881116675513

Griffiths, R. R., Johnson, M. W., Richards, W. A., Richards, B. D., McCann, U., \& Jesse, R. (2011). Psilocybin occasioned mystical-type experiences: Immediate and persisting doserelated effects. Psychopharmacology (Berl), 218(4), 649-665. doi:10.1007/s00213-011-2358-5

Griffiths, R. R., Johnson, M. W., Richards, W. A., Richards, B. D., Jesse, R., MacLean, K. A., Barrett, F. S., Cosimano, M. P., \& Klinedinst, M. A. (2018). Psilocybin-occasioned mystical-type experience in combination with meditation and other spiritual practices produces enduring positive changes in psychological functioning and in trait measures of prosocial attitudes and behaviors. Journal of Psychopharmacology, 32(1), 49-69. doi:10.1177/0269881117731279

Griffiths, R. R., Richards, W. A., McCann, U., \& Jesse, R. (2006). Psilocybin can occasion mystical-type experiences having substantial and sustained personal meaning and spiritual significance. Psychopharmacology (Berl), 187(3), 268-283. doi:10.1007/s00213-006-0457-5

Halpern, J. H., Sherwood, A. R., Hudson, J. I., Yurgelun-Todd, D., \& Pope, H. G., Jr. (2005). Psychological and cognitive effects of long-term peyote use among Native Americans. Biological Psychiatry, 58(8), 624-631. doi:10.1016/j.biopsych.2005.06.038

Harman, W. W., McKim, R. H., \& Mogar, R. E. (1966). Psychedelic agents in creative problem-solving: A pilot study. Psychological Reports, 19(1), 211-227. doi:10.2466/pr0.1966. 19.1.211

Hendricks, P. S. (2018). Awe: A putative mechanism underlying the effects of classic psychedelic-assisted psychotherapy. International Review of Psychiatry, 30(4), 331-342. doi:10.1080/ 09540261.2018.1474185

Hendricks, P. S., Crawford, M. S., Cropsey, K. L., Copes, H., Sweat, N. W., Walsh, Z., \& Pavela, G. (2018). The relationships of classic psychedelic use with criminal behavior in the United States adult population. Journal of Psychopharmacology, 32(1), 37-48. doi:10.1177/0269881117735685

Hendricks, P. S., Thorne, C. B., \& Clark, C. B. (2015). Classic psychedelic use is associated with reduced psychological distress and suicidality in the United States adult population. Journal of Psychopharmacology, 29(3), 280-288. doi:10.1177/ 0269881114565653

Howell, A. J., Dopko, R. L., Passmore, H.-A., \& Buro, K. (2011). Nature connectedness: Associations with well-being and mindfulness. Personality and Individual Differences, 51(2), 166-171. doi:10.1016/j.paid.2011.03.037

Johansen, P., \& Krebs, T. S. (2015). Psychedelics not linked to mental health problems or suicidal behavior: A population study. Journal of Psychopharmacology, 29(3), 270-279. doi:10.1177/0269881114568039

Johnstad, P. G. (2018). Powerful substances in tiny amounts: An interview study of psychedelic microdosing. Nordic Studies on Alcohol and Drugs, 35(1), 39-51. doi:10.1177/1455072 517753339

Kamitsis, I., \& Francis, A. J. (2013). Spirituality mediates the relationship between engagement with nature and psychological wellbeing. Journal of Environmental Psychology, 36, 136-143. doi:10.1016/j.jenvp.2013.07.013

Krebs, T. S., \& Johansen, P. (2013). Psychedelics and mental health: A population study. PLoS One, 8(8), e63972. doi:10.1371/journal.pone.0063972

Lee, K., Ashton, M. C., Choi, J., \& Zachariassen, K. (2015). Connectedness to nature and to humanity: Their association and personality correlates. Frontiers in Psychology, 6, 1003. doi:10.3389/fpsyg.2015.01003 
Lerner, M., \& Lyvers, M. (2006). Values and beliefs of psychedelic drug users: A cross-cultural study. Journal of Psychoactive Drugs, 38(2), 143-147. doi:10.1080/02791072.2006. 10399838

Ly, C., Greb, A. C., Cameron, L. P., Wong, J. M., Barragan, E. V., Wilson, P. C., Burbach, K. F., Soltanzadeh Zarandi, S., Sood, A., Paddy, M. R., Duim, W. C., Dennis, M. Y., McAllister, A. K., Ori-McKenney, K. M., Gray, J. A., \& Olson, D. E. (2018). Psychedelics promote structural and functional neural plasticity. Cell Reports, 23(11), 3170-3182. doi:10.1016/ j.celrep.2018.05.022

Lyons, T., \& Carhart-Harris, R. L. (2018). Increased nature relatedness and decreased authoritarian political views after psilocybin for treatment-resistant depression. Journal of Psychopharmacology, 32(7), 811-819. doi:10.1177/02698811 17748902

Mackay, C. M. L., \& Schmitt, M. T. (2019). Do people who feel connected to nature do more to protect it? A metaanalysis. Journal of Environmental Psychology, 65, 101323. doi:10.1016/j.jenvp.2019.101323

MacLean, K. A., Johnson, M. W., \& Griffiths, R. R. (2011). Mystical experiences occasioned by the hallucinogen psilocybin lead to increases in the personality domain of openness. Journal of Psychopharmacology, 25(11), 1453-1461. doi:10.1177/ 0269881111420188

Martyn, P., \& Brymer, E. (2016). The relationship between nature relatedness and anxiety. Journal of Health Psychology, 21(7), 1436-1445. doi:10.1177/1359105314555169

Mayer, F. S., \& Frantz, C. M. (2004). The connectedness to nature scale: A measure of individuals' feeling in community with nature. Journal of Environmental Psychology, 24(4), 503-515. doi:10.1016/j.jenvp.2004.10.001

Mayer, F. S., Frantz, C. M., Bruehlman-Senecal, E., \& Dolliver, K. (2008). Why is nature beneficial? The role of connectedness to nature. Environment and Behavior, 41(5), 607-643. doi:10.1177/0013916508319745

McCallum, M. L. (2015). Vertebrate biodiversity losses point to a sixth mass extinction. Biodiversity and Conservation, 24(10), 2497-2519. doi:10.1007/s10531-015-0940-6

McMahan, E. A., Estes, D., Murfin, J. S., \& Bryan, C. M. (2018). Nature connectedness moderates the effect of nature exposure on explicit and implicit measures of emotion. Journal of Positive Psychology and Wellbeing, 2(2), 1-21. Retrieved from http://www.journalppw.com/index.php/JPPW/article /view/54

Narby, J. (2002). Shamans and scientists. In C. S. Grob (Ed.), Hallucinogens: A reader (pp. 159-163). New York, NY: Putnam.

Neaman, A., Otto, S., \& Vinokur, E. (2018). Toward an integrated approach to environmental and prosocial education. Sustainability, 10(3), 1-11. doi:10.3390/su10030583

Nichols, D. E. (2016). Psychedelics. Pharmacological Reviews, 68(2), 264-355. doi:10.1124/pr.115.011478

Nisbet, E. K., \& Zelenski, J. M. (2014). Nature relatedness and subjective well-being. In A. C. Michalos (Ed.), Encyclopedia of quality of life and well-being research. Dordrecht, The Netherlands: Springer.

Nisbet, E. K., Zelenski, J. M., \& Murphy, S. A. (2011). Happiness is in our nature: Exploring nature relatedness as a contributor to subjective well-being. Journal of Happiness Studies, 12(2), 303-322. doi:10.1007/s10902-010-9197-7
Nour, M. M., Evans, L., \& Carhart-Harris, R. L. (2017). Psychedelics, personality and political perspectives. Journal of Psychoactive Drugs, 49(3), 182-191. doi:10.1080/02791072. 2017.1312643

Ona, G., Kohek, M., Massaguer, T., Gomariz, A., Jiménez, D. F., Dos Santos, R. G., Hallak, J. E. C., Alcázar-Córcoles, M. Á., \& Bouso, J. C. (2019). Ayahuasca and public health: Health status, psychosocial well-being, lifestyle, and coping strategies in a large sample of ritual ayahuasca users. Journal of Psychoactive Drugs, 51(2), 135-145. doi:10.1080/02791072. 2019.1567961

Otto, S., \& Pensini, P. (2017). Nature-based environmental education of children: Environmental knowledge and connectedness to nature, together, are related to ecological behaviour. Global Environmental Change, 47, 88-94. doi:10.1016/j.gloenvcha. 2017.09.009

Pahnke, W. N. (1963). Drugs and mysticism: An analysis of the relationship between psychedelic drugs and the mystical consciousness: A thesis (Unpublished PhD Thesis). Harvard University, Cambridge, MA.

Piff, P. K., Dietze, P., Feinberg, M., Stancato, D. M., \& Keltner, D. (2015). Awe, the small self, and prosocial behavior. Journal of Personality and Social Psychology, 108(6), 883-899. doi:10.1037/pspi0000018

Polito, V., \& Stevenson, R. J. (2019). A systematic study of microdosing psychedelics. PLoS One, 14(2), e0211023. doi:10.1371/journal.pone.0211023

Pritchard, A., Richardson, M., Sheffield, D., \& McEwan, K. (2019). The relationship between nature connectedness and Eudaimonic well-being: A meta-analysis. Journal of Happiness Studies, 1-23. Advance online publication. doi:10.1007/ s10902-019-00118-6

Prochazkova, L., Lippelt, D. P., Colzato, L. S., Kuchar, M., Sjoerds, Z., \& Hommel, B. (2018). Exploring the effect of microdosing psychedelics on creativity in an open-label natural setting. Psychopharmacology, 235(12), 3401-3413. doi:10. 1007/s00213-018-5049-7

Restall, B., \& Conrad, E. (2015). A literature review of connectedness to nature and its potential for environmental management. Journal of Environmental Management, 159, 264-278. doi:10.1016/j.jenvman.2015.05.022

Richardson, M., \& Sheffield, D. (2015). Reflective self-attention: A more stable predictor of connection to nature than mindful attention. Ecopsychology, 7(3), 166-175. doi:10.1089/eco. 2015.0010

Ross, S., Bossis, A., Guss, J., Agin-Liebes, G., Malone, T., Cohen, B., Mennenga, S. E., Belser, A., Kalliontzi, K., Babb, J., Su, Z., Corby, P., \& Schmidt, B. L. (2016). Rapid and sustained symptom reduction following psilocybin treatment for anxiety and depression in patients with life-threatening cancer: A randomized controlled trial. Journal of Psychopharmacology, 30(12), 1165-1180. doi:10.1177/0269881116675512

Rudd, M., Vohs, K. D., \& Aaker, J. (2012). Awe expands people's perception of time, alters decision making, and enhances well-being. Psychological Science, 23(10), 1130-1136. doi:10.1177/0956797612438731

Savage, C., Fadiman, J., \& Mogar, R. (1966). The effects of psychedelic (LSD) therapy on values, personality, and behavior. International Journal of Neuropsychiatry, 2(3), 241-254. 
Schmid, Y., \& Liechti, M. E. (2018). Long-lasting subjective effects of LSD in normal subjects. Psychopharmacology, 235(2), 535-545. doi:10.1007/s00213-017-4733-3

Sessa, B. (2008). Is it time to revisit the role of psychedelic drugs in enhancing human creativity? Journal of Psychopharmacology, 22(8), 821-827. doi:10.1177/0269881108091597

Sessa, B. (2018). The 21st century psychedelic renaissance: Heroic steps forward on the back of an elephant. Psychopharmacology (Berl), 235(2), 551-560. doi:10.1007/s00213-017-4713-7

Smigielski, L., Kometer, M., Scheidegger, M., Krähenmann, R., Huber, T., \& Vollenweider, F. X. (2019). Characterization and prediction of acute and sustained response to psychedelic psilocybin in a mindfulness group retreat. Scientific Reports, 9, 1-13. doi:10.1038/s41598-019-50612-3

Smigielski, L., Scheiddegger, M., Kometer, M., \& Vollenweider, F. X. (2019). Psilocybin-assisted mindfulness training modulates self-consciousness and brain default mode network connectivity with lasting effects. NeuroImage, 196, 207-215. doi:10.1016/j.neuroimage.2019.04.009

Soler, J., Elices, M., Franquesa, A., Barker, S., Friedlander, P., Feilding, A., Pascual, J. C., \& Riba, J. (2016). Exploring the therapeutic potential of ayahuasca: Acute intake increases mindfulness-related capacities. Psychopharmacology, 233(5), 823-829. doi:10.1007/s00213-015-4162-0

Studerus, E., Kometer, M., Hasler, F., \& Vollenweider, F. X. (2011). Acute, subacute and long-term subjective effects of psilocybin in healthy humans: A pooled analysis of experimental studies. Journal of Psychopharmacology, 25(11), 1434-1452. doi:10.1177/0269881110382466

Sweat, N. W., Bates, L. W., \& Hendricks, P. S. (2016). The associations of naturalistic classic psychedelic use, mystical experience, and creative problem solving. Journal of Psychoactive Drugs, 48(5), 344-350. doi:10.1080/02791072. 2016.1234090

Tam, K.-P. (2013). Concepts and measures related to connection to nature: Similarities and differences. Journal of Environmental Psychology, 34, 64-78. doi:10.1016/j.jenvp.2013.01.004

Uthaug, M. V., Lancelotta, R., van Oorsouw, K., Kuypers, K. P. C., Mason, N., Rak, J., Šuláková, A., Jurok, R., Maryška, M., Kuchař, M., Páleníček, T., Riba, J., \& Ramaekers, G. (2019).
A single inhalation of vapor from dried toad secretion containing 5-methoxy- $N, \quad N$-dimethyltryptamine (5-MeO-DMT) in a naturalistic setting is related to sustained enhancement of satisfaction with life, mindfulness-related capacities, and a decrement of psychopathological symptoms. Psychopharmacology, 236(9), 2653-2666. doi:10.1007/s00213-019-05236-w

Uthaug, M. V., van Oorsouw, K., Kuypers, K. P. C., van Boxtel, M., Broers, N. J., Mason, N. L., Toennes, S. W., Riba, J., \& Ramaekers, J. G. (2018). Sub-acute and long-term effects of ayahuasca on affect and cognitive thinking style and their association with ego dissolution. Psychopharmacology (Berl), 235(10), 2979-2989. doi:10.1007/s00213-018-4988-3

Van Gordon, W., Shonin, E., \& Richardson, M. (2018). Mindfulness and nature. Mindfulness, 9(5), 1655-1658. doi:10.1007/ s12671-018-0883-6

Voss, P., Thomas, M. E., Cisneros-Franco, J. M., \& de Villers-Sidani, E. (2017). Dynamic brains and the changing rules of neuroplasticity: Implications for learning and recovery. Frontiers in Psychology, 8, 1657. doi:10.3389/fpsyg.2017. 01657

Walsh, R. (1982). Psychedelics and psychological well-being. Journal of Humanistic Psychology, 22(3), 22-32. doi:10.1177/ 0022167882223004

Weinstein, N., Przybylski, A. K., \& Ryan, R. M. (2009). Can nature make us more caring? Effects of immersion in nature on intrinsic aspirations and generosity. Personality and Social Psychology Bulletin, 35(10), 1315-1329. doi:10.1177/ 0146167209341649

Whitburn, J., Linklater, W., \& Abrahamse, W. (2019). Metaanalysis of human connection to nature and proenvironmental behaviour. Conservation Biology. Advance online publication. doi:10.1111/cobi.13381

Zelenski, J. M., \& Nisbet, E. K. (2014). Happiness and feeling connected: The distinct role of nature relatedness. Environment and Behavior, 46(1), 3-23. doi:10.1177/0013916512451901

Zhang, J. W., Howell, R. T., \& Iyer, R. (2014). Engagement with natural beauty moderates the positive relation between connectedness with nature and psychological well-being. Journal of Environmental Psychology, 38, 55-63. doi:10.1016/ j.jenvp.2013.12.013 